\title{
Infância monstruosa
}

Monstrous Childhood

\section{Alcebiades Diniz Miguel}

Resumo: A passagem do tempo e o desenvolvimento em etapas, assegurado ao ser humano, não costuma ser um atributo do monstro. Imagem perene que não se altera e que obedece outra possibilidade temporal, encarnação de estereótipos ancestrais ou visão delirante de uma continuidade ameaçadora, o monstro quando encarnado no processo histórico deve, necessariamente, abandonar sua infância. Contudo, há variedade nesse processo; analisaremos, neste artigo, duas dessas variedades, ambas leituras inspiradas da narrativo do Golem: o Golem de Gustav Meyrink e a "Sarpele cu Ochelari" de Horia Bonciu.

Palavras-chave: Infância. Monstro. Golem.

Abstract: The passing time, the development in structured stages, assured in the human being case, it's not usually a monster attribute. Perennial image that does not change and that obeys other temporal lineage, incarnation of ancient stereotypes or delusional vision of a threatening continuity, the monster when turned to physical form in the historical process must necessarily abandon its childhood. However, there is some chance for the innovation in this process; in this article, our analysis will be focused in two of these innovative varieties, both readings inspired by the Golem traditional narrative: Golem by Gustav Meyrink and Horia Bonciu "Sarpele cu Ochelari".

Keywords: Childhood. Monster. Golem.

A curiosidade infantil desses seres se exprime em suas dimensões notavelmente escassas; querem deixar o cômodo sem perceber o lado irônico de tal conduta mas, de um momento para outro, saias e pernas se iluminam graças a poderosos fogos de artifício. (Trost, Le Même du Même). ${ }^{1}$

É bastante emblemática a primeira cena do filme Blade Runner, o caçador de andróides (Blade Runner, 1982), de Ridley Scott, na qual ocorre o "teste psicológico" em um dos perigosos andróides foragidos da Tyrell Corporation, Leon. Nos primeiros momentos dessa cena, temos uma visão da vasta, titânica e inteiramente artificial cidade, com suas torres de petróleo disparando chamas para um céu enegrecido, no 
qual há espaço apenas para as poderosas luzes de holofotes. Em uma pequena sala da torre central, um inexpressivo funcionário corporativo realiza testes em série com funcionários recém contratados, avaliando se seriam andróides replicantes se fazendo passar por humanos. De fato, os replicantes são em termos de aparência, idênticos aos humanos - embora possuam força e resistência sobre-humanas, embora sejam produtos de validade curta, tendo apenas cinco anos de "vida". O que distingue o natural (humano) do fabricado (andróide) são as reações psicológicas, relacionadas à memória e à subjetividade, elementos complexos cujo desenvolvimento a curta vida da máquina (que aparentemente já nasce adulta, pronta, sem a necessidade de nenhum tipo de interação para o aprendizado e/ou o desenvolvimento cognitivo) não permitiria.

Nesse sentido, o teste apresentado - denominado Voight-Kampff tanto no filme quanto no livro que lhe serviu de base, escrito por Philip K. Dick - se concentra justamente na tentativa de extrair reações acionadas pela memória, pela capacidade imaginativa e pelas emoções humanas, elementos que a máquina programada não seria capaz de replicar.

Assim, a primeira pergunta do investigador é hipotética: se Leon estivesse caminhando no deserto e visse um jabuti visse um jabuti rastejando em sua direção, o virasse de barriga para cima e ficasse apenas observando a agonia do animal, qual seria o motivo dessa atitude. Leon demonstra, fisicamente, seu desconforto diante da pergunta que aciona mecanismos imagéticos e emotivos da mente humana: transpira, gagueja, as pupilas dilatadas. De forma semelhante, o andróide interrompe, por diversas vezes, o investigador seja para tentar se apoiar em índices e referências da pragmática discursiva (onde ficaria o tal deserto, o que alguém estaria fazendo nesse lugar, o que seria um jabuti) seja para bloquear a progressão perturbadora da questão (qual momento o teste de fato começaria, a natureza do teste seria a mesma de uma armadilha, a situação hipotética da pergunta seria impossível e por isso imoral). A resposta de Leon à segunda pergunta do investigador ("descreva, em palavras soltas, apenas as coisas boas que vêm à sua mente a respeito de sua mãe"), dois tiros após dizer "vou te contar sobre a minha mãe", finaliza brutalmente um teste que deveria ter 30 questões. ${ }^{2} \mathrm{O}$ monstro não possui espaço, em sua paisagem mental, para questões relacionadas à maternidade ou o complexo de Édipo; mesmo quando o monstro possui uma origem parental definida - como no caso do monstro do poema épico anglo saxão Beowulf - ela apenas reafirma a natureza artificial do monstro, uma essência que se coloca em oposição às determinações usuais da Natureza e da Cultura.

Entre os elementos que compõem a dramaturgia do horror da monstruosidade, Luiz Nazario indica duas formas aparentemente conflitantes, mas eventualmente complementares das relações do monstro com suas origens: a unicidade e a 
hereditariedade. No primeiro caso, o monstro é um ser único, de origem misteriosa, que se transforma em "força devastadora da natureza" (NAZARIO, 1998, p. 34). Já a hereditariedade garante que o Mal seja uma herança do sangue: a reprodução da monstruosidade ocorre por contágio, por contato direto com os fluidos corporais da criatura (NAZARIO, 1998, p. 39). A contradição entre o único e o disseminado, nesse caso, caracterizam de forma clara como a origem do monstro está livre de qualquer tipo de determinação ou necessidade de desenvolvimento - a monstruosidade não possui infância, nem emotividade paternal ou maternal. A substituição do conflito essencial que é o Complexo de Édipo, na constituição da identidade do monstro, acaba substituído por percepções irracionais, temíveis: o horror sagrado e a maldição.

Portanto, o monstro encarna o processo de desterritorialização por excelência, um exilado em relação ao universo que o cerca, pois a própria Natureza parece excluí-lo. A identidade do monstro, nesse sentido, se aproxima daquela do povo judeu - um povo de refugiados, expulsos de sua terra e que vagam, errantes, sem um local no qual possa deitar raízes, restabelecer sua continuidade com a Natureza circundante, cessar seu deslocamento embora, ao mesmo tempo, alimentem uma nostalgia utópica de um outro lugar, um espaço ao mesmo tempo mítico e histórico. Essa nostalgia utópica permite a construção de uma identidade de uma maneira mais clara e sistemática que o enraizamento em uma tradição, um solo, uma linhagem específica. Não por acaso, os nazistas codificaram o povo judeu em formas e caricaturas específicas, um complexo imaginário dinâmico e potente como uma máquina, que inclusive migrou (preservando suas características essenciais) do campo das estampas e ilustrações de jornais e panfletos para a fotografia e cinema (NAZARIO, 2010, p. 18-19).

De certa forma, o antissemita, ao encarar o judeu como um monstro fantástico portanto, se origem, sem infância, uma criatura cujos períodos de gestação, formação e constituição parecem imbricados - padece de um problema mimético: no antissemitismo, a projeção da imagem do outro sofre de um processo doentio de repulsão. Como afirmaram Theodor Adorno/Max Horkheimer, é em uma falsa projeção que o pensamento do antissemita se baseia: “Os impulsos que o sujeito não admite como seus e que, no entanto, lhe pertencem são atribuídos ao objeto: a vítima em potencial." (ADORNO; HORKHEIMER, 2006, p. 154).

O monstro, igualmente, possui algo de permanente, instantâneo, constante: a infância não é de sua natureza. Como os microrganismos, o monstro parece se reproduzir através de um processo de replicação, de geração de si mesmo através de um processo assexuado de cissiparidade. Assim, pela ótica tenebrosa do agressor, os novos monstros surgem do nada como organismos acabados, prontos, transformando-se em alvo liberado para todo o tipo de violência e perversidade, uma 
vez que seu desenvolvimento não se processa em estágios - a criança e o adulto do grupo identificado à monstruosidade pertencem a um continuum, e o tratamento diferenciado que um e outro deveriam ter é apenas uma ilusão. Daí as cenas de horror que o antissemitismo produz desde os pogroms e assaltos aos guetos judaicos ainda na Idade Média, quando crianças judias eram jogadas contra as paredes das casas para terem sua cabeça esmagada ${ }^{3}$ até a matança de crianças judias durante o Holocausto. Para se chegar a esse ponto - do assassinato em escala industrial de seres já não mais vistos como humanos em nenhum outro traço que não seja uma aparência enganadora e mentirosa - a propaganda sistemática, que promoveu uma fantástica e apocalíptica visão do povo votado para a destruição e realizou uma espécie de gigantesca suspensão a descrença entre os perpetradores de tais crimes, para que seus atos fossem vistos não como assassinatos coletivos, mas como atividades de saneamento, em uma luta inglória contra um inimigo que possui a mesma essência e forma que uma doença infecciosa.

De certa forma, as mais radicais manifestações antissemitas foram atualizações na realidade concreta de certa mitologia na qual o judeu ocupava a posição de representante e/ou de materialização do Mal absoluto - narrativas míticas alimentadas por discursos de propaganda. Segundo Luiz Nazario, ao comentar a respeito do espantoso em homenagem ao agitador antissemita Theodor Fritsch, o "monumento antissemita" em que se inscreve na pedra, de forma indelével, toda esse mecanismo narrativo genocida:

Houve a partir de 29 de janeiro de 1939, quando Hitler 'profetizou' o extermínio dos judeus, muitas caricaturas e um bom número de filmes explicitamente antissemitas. $\mathrm{O}$ documentário Der ewige Jude ('O eterno judeu' ou 'O judeu errante') comparou os 'judeus' do gueto a ratos transmissores da peste; a cartilha Der Giftpilz ('O cogumelo venenoso') pintouos como cogumelos venenosos; o filme de entretenimento $O$ Judeu Süß (O judeu Suss, 1941), de Veit Harlan, mostrou o 'judeu' como um vilão que terminava, por justiça, enforcado; e a caricatura $\mathrm{O}$ parasita apresentou-o como um verme horrendo. Mas o extremismo dessas propagandas não atingiu, pela própria natureza de seus meios, o efeito de perenidade conseguido pelo monumento antissemita, que materializou de fato a metáfora do extermínio, antes limitada pelo caráter volátil da linguagem oral-gráfica, pela difusão 'intimista' dos panfletos e pela ambigüidade do naturalismo cinematográfico. A inscrição na pedra - 'A luta contra o judeu é uma questão de honra' - sintetiza a motivação singular do Holocausto. (NAZARIO, 2015). 
Contudo, se todo o povo judeu, dentro da perspectiva antissemita, transforma-se em monstro imaginário, o que dizer dos monstros imaginários da tradição judaica? Teriam tais monstros algo como uma infância, um desenvolvimento sequencial até sua forma monstruosa ou nasceriam e permaneceriam monstros até o momento de seu extermínio? De fato, não se trata de uma questão ociosa: é sabido que o monstro costuma possuir uma origem, mas não uma infância. $\mathrm{O}$ mito, a tradição, a narrativa originária circunscrevem o monstro no tempo e no espaço, mas silenciam a respeito dos eventuais dramas de sua infância e adolescência. Esse é o caso de Polifemo, o ciclope que surge no nono livro da Odisséia de Homero - filho do deus Posêidon e da ninfa Teosa, que devora a tropa de Odisseu desrespeitando um dos códigos mais fundamentais da humanidade, as regras de acolhimento: "Assim falei, e não me respondeu com impiedoso ânimo/mas, de súbito, sobre os companheiros estendeu a mão/e, tendo dois agarrado, como cachorrinhos ao chão/arrojou-os: miolos escorriam no chão e molhavam o solo." (HOMERO, 2014, p. 290).

O gigantesco ciclope, que esmaga homens como se fossem cães antes de devorá-los, de forma muito diferente de seu antagonista, o Odisseu, não possui sinais do passado em seu corpo, marcas da formação de seu caráter. Sempre igual, parece já ter surgido exatamente como descrito na Odisséia. Da mesma forma, Lúcifer - o monstro mais tradicional do Ocidente cristão - possui uma origem dita angelical pela tradição celebrada, por exemplo, pela Divina Comédia de Dante - "Se belo foi quão feio ora é o seu modo,/e contra seu feitor ergueu a frente,/ só dele proceder deve o mal todo." (ALIGHIERI, 1998, p. 226).

Talvez tenha sido por esse motivo que o filósofo Vilém Flusser tenha justamente trabalhado uma longa infância para o diabo - um dos nomes de Lúcifer e materialização geral da denominação dada ao rei do inferno, ao senhor dos abismos, do momento em que nasceu, no instante mesmo da criação (para Flusser, o Senhor criou ao mesmo tempo o mundo fenomenal e o diabo) até suas primeiras brincadeiras e folguedos no amplo universo dos fenômenos (FLUSSER, 2006, p. 3152). De igual modo, os monstros do Antigo Testamento surgem como reminiscências de um passado tormentoso, portanto como seres contínuos, que um dia conviveram belicosamente com o Criador; o Beemot e o Leviatã bíblicos, no Livro de Jó, embora sejam caracterizados como um animal como outros, um fruto da criação como o próprio homem, possuem contudo algo de descomunal, monstruoso, mítico, um elemento que os inviabiliza como espécies e os transforma em seres únicos: "É a obra-prima de Deus. / O seu Criador o ameaça com a espada" (BÍBLIA DE JERUSALÉM, 1992, p. 938).

O Drácula conforme a invenção do escritor irlandês Bram Stoker, igualmente surge como um ser ahistórico ainda que baseado em um personagem histórico que contamina suas vítimas e se reproduz novamente nelas. Mesmo em suas mais 
elaboradas reinvenções - como é o caso dos romances The Historian de Elizabeth Kostova e The Dracula Papers, Book I: The Scholar's Tale, de Reggie Oliver - o ser humano que gerou a criatura desaparece em prol de uma mitologia ainda mais ampla e complexa. O monstro, portanto, além de não ser uma criatura que necessite atravessar algum tipo de desenvolvimento - por exemplo, da falta da linguagem para o domínio da linguagem - também é marcada por sua unicidade, ainda que essa unicidade seja reafirmada em uma multiplicidade que serve apenas para tornar mais claro o caráter contagioso do monstro, nem sempre evidente, e ressaltar por outras vias a mesma unicidade temerosa que a leitura do Leviatã bíblico eventualmente inspira; os muitos vampiros gerados por Drácula são, na verdade, moldados à forma monstruosa única de seu mestre, cópias em menor escala de um Mal maior. ${ }^{4}$

Nesse sentido, os monstros da tradição judaica - ultrapassando a Bíblia - guardam leituras riquíssimas no que tange à gestação, criação e ao desenvolvimento. Nesse sentido, talvez a mais rica construção monstruosa do imaginário judaico seja o golem: criatura feita de barro e de palavra inscrita, forma que mimetiza e ironiza o homem e a própria Criação, escravo mecânico surgido das maquinações de um cabalista e arma de defesa da oprimida comunidade judaica encerrada no gueto de Praga, ser que premedita o robô e o clone criado por engenharia genética. As manifestações, leituras e releituras do golem são as mais diversas - feito possível graças à natureza polissêmica dessa narrativa mítica que segue, como uma sombra, as narrativas igualmente prenhe de sentidos da Bíblia, como bem percebeu Lyslei Nascimento: "A lenda do Golem faz parte desse corpus místico que recorre às Escrituras para alcançar uma ascese do homem em relação às suas limitações." (NASCIMENTO, 2004, p. 16). A polissemia acompanha o próprio sentido do termo golem, que designa ideias/elementos próximos (larva, pupa) e distantes (robô, pessoa estúpida e/ou desajeitada). ${ }^{5}$ Tal criatura, estranha e multiforme, tão rica em leituras diversas e conflitantes, oferece um corpus quase infinito de narrativas (lendas, ditos, causos, contos, romances). Optaremos, contudo, por duas narrativas em especial desse imenso corpus: o romance Der Golem (1914) de Gustav Meyrink e a recriação realizada pelo pesquisador e ficcionista Andrew Condous - pois a obra original se perdeu ou não passou de uma etapa inicial de planificação, algo que jamais ficará claro - de "Sarpele cu ochelari", obra que talvez tenha sido escrita pelo "Golem de Bucareste", Horia Bonciu. São obras originais, que revelam como o monstro judaico por excelência - o golem - facilita releituras, apropriações (mesmo algumas contaminadas de certa visão anti-judaica) e deslocamentos; no meio de todos esses processos, surgem interessantes percepções da infância e da origem do monstro, muitas vezes subvertendo a percepção original e sólida - numa palavra, unitária - do monstro que descrevemos anteriormente.

Nossa primeira parada, portanto, acontece na Praga no ano de início da Primeira Guerra Mundial, com o Golem de Gustav Meyrink (1868-1932). Meyrink foi um autor 
peculiar em uma época em que tal adjetivo era bastante empregado - banqueiro, réu condenado e encarcerado, satirista com especial predileção pelo grotesco, ocultista. O período em que esteve preso devido a supostas irregularidades financeiras em 1902, seria preso para averiguações - que levariam à soltura do autor, que se comprovou inocente das acusações - aniquilaria a encarnação do banqueiro/bon vivant, facilitando a emergência do satirista e do místico-ocultista, ambos fundamentais na composição de uma obra como Der Golem ou seus ainda mais intrincados romances posteriores. De qualquer forma, o horror diante de opressivas autoridades e a simpatia pelos marginais marcaria para sempre o Meyrink devastado que deixou a prisão; de fato, um dos momentos mais tocantes de Der Golem é justamente o segmento fortemente influenciado por Dickens, "A história do honorável Dr. Hulbert e sua brigada" (MEYRINK, 1986, p. 38-43). A simpatia pela marginalidade somada ao fascínio pelas mais diversas correntes místico-ocultista - incluindo a cabala - talvez tenham sido essenciais para Meyrink se aproximar da tradição judaica e trabalhar sua leitura pessoal do golem. A produção do livro, contudo, foi tumultuada desde sua gestação no início de 1907: um verdadeiro calvário para o autor que, segundo comentário de E. F. Bleiler, adicionava tantos elementos complicados e ampliava em tanto tempo a elaboração do romance que chegou a perder seu ilustrador original, o expressionista Alfred Kubin (BLEILER, 1986, p. x-xii). Com ajuda de conhecidos e de arcanos esquemas e diagramas (elaborados provavelmente, segundo Bleiler, em tabuleiros de xadrez, uma paixão do autor), Meyrink conseguiu enxugar a trama aos limites e dimensões factíveis. Até mesmo o novo ilustrador, encarregado de substituir Kubin - que, entrementes, utilizou as ilustrações criadas para Der Golem em seu próprio romance, Die andere Seite. Ein phantastischer Roman (1908) -, Hugo Steiner-Prag conseguiu captar as nuances alienígenas desse golem que se esgueira pelas sombrias ruas de Praga, exercendo influência definitiva no nascente cinema expressionista alemão, como podemos comprovar na imagem a seguir:

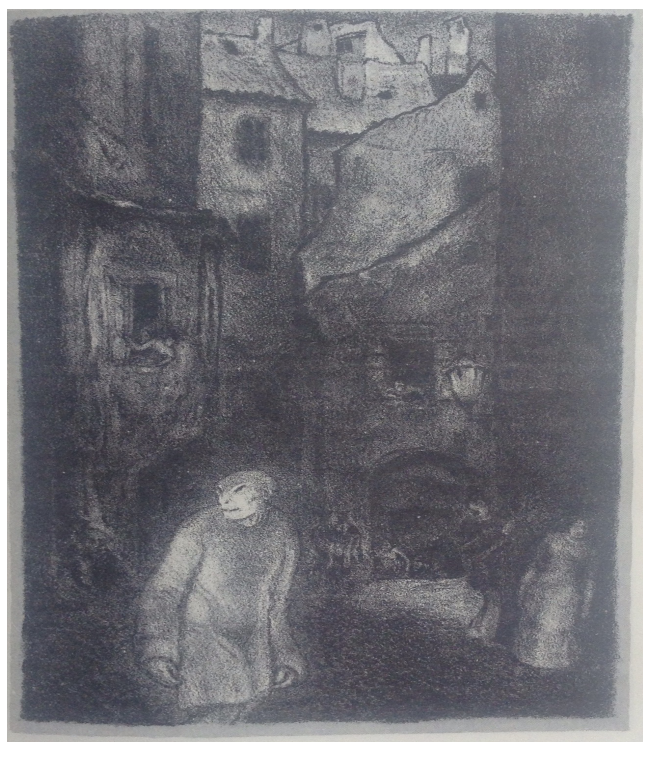


Tal golem estranhamente humanóide e furtivo captado nas litografias de Hugo Steiner-Prag representa com bastante acuidade a percepção dada por Meyrink para a criatura: uma espécie de representação coletiva da alma do gueto judaico de Praga, em seus mais diversos aspectos. A lenda na visão de Meyrink afasta-se da leitura tradicional associada ao imaginário do embrião - um dos sentidos mais usuais para a palavra golem - transmutando-se em um elemento cíclico, que surge de 33 em 33 anos, um ser de vagos traços orientais que realiza uma jornada sem objetivo definido e desaparece em um beco do gueto. O golem de Meyrink é uma construção fantasiosa de uma mente cristã, com pouco contato com a tradição judaica - trata-se de um "golem sineiro" que replica algo do corcunda que aparece no célebre NotreDame de Paris (1831), de Victor Hugo, criação malsucedida como nas fantasias românticas de aprendiz de feiticeiro foi bem dimensionada por pesquisadores como Élcio Cornelsen (CORNELSEN, 2004, p. 57-58). De fato, como escreveu Bleiler, o "golem poderia ter muitos outros nomes sem grades perdas" (BLEILER, 1986, p. xii). A transformação de uma narrativa tradicional de grande alcance e complexidade em mito privado, realizada por Meyrink e tão criticada por historiadores do judaísmo como Gershom Scholem, possui uma face deletéria logo perceptível nos estereótipos construídos em torno de figuras que o imaginário cristão já forjara. Assim, diante do judeu sábio e bondo (um estereótipo positivo) encarnado por Schemajah Hillel, se contrapõem figuras como Aaron Wassertrum, o vendedor de sucata assassino e sua filha, Rosina, a bela judia que enlouquece seus pretendentes e encarna a luxúria com ferocidade semelhante àquela empregada por $\mathrm{H}$. H. Ewers em um romance contemporâneo a Der Golem e de racismo mais evidente, Alraune (1911). ${ }^{6}$

A criatura de Meyrink, assim, representa os estereótipos de um povo - que o próprio autor acaba por reproduzir -, mas transcende esse nascimento coletivo ao ser evocado, transformando-se em duplo não apenas do protagonista Athanasius Pernath, mas dos transeuntes na rua, de qualquer habitante do gueto. Em um percurso inverso ao de Drácula, o monstro absorve memórias, história, sonhos e visões de cada uma de suas duplicações, daí a necessidade de se multiplicar na trama de Meyrink os sonhos, histórias, pesadelos. Mais que um mito pessoal, o golem distorcido de Meyrink se transforma em "alma das ruas", não apenas do gueto, mas de toda a cidade de Praga em uma réplica ao sentimento expresso por João do Rio: "Nós somos irmãos, nós nos sentimos parecidos e iguais; nas cidades, nas aldeias, nos povoados, não porque soframos, com a dor e os desprazeres, a lei e a polícia, mas porque nos une, nivela e agremia o amor da rua." (RIO, 2015). Gestado na fantasia romântica, a criatura surge para cumprir peregrinações cíclicas e para assumir a duplicação dos transeuntes e daqueles que a evocam, absorvendo a personalidade de cada um deles; a própria cidade, contínua, permanente ainda quando destruída, torna-se a criatura. A infância do monstro transforma-se nas múltiplas idades da 
cidade, conforme experimentada subjetivamente por seus habitantes - não por acaso a narrativa principal do golem no romance de Meyrink são as lembranças de juventude do artesão Zwakh (MEYRINK, 1986, p. 27-28).

Segundo Élcio Cornelsen, Der Golem obteve sucesso considerável, pois apenas entre 1915 e 1922 "foram vendidos 165.000 exemplares, sem dúvida, um número expressivo para a época" (CORNELSEN, 2004, p. 56). Tanto sucesso - depois replicado em sucessivas versões cinematográficas da criatura - motivou leituras posteriores, mesmo vanguardistas, ainda mais pessoais do golem. Esse é o caso do projeto do escritor romeno Horia Bonciu (1893-1950), Sarpele cu Ochelari - que poderíamos traduzir literalmente como "serpente com óculos" ou, na opção de Andrew Condous, "The Cobra", que explica que a expressão romena que designa as cobras mais venenosas, as najas (CONDOUS, 2015, p. 42). Bonciu foi um excêntrico e revolucionário autor romeno de ascendência judaica nascido em Iași que cultivou o gosto pelo pseudônimo, pela flutuação da identidade através da instabilidade na nomeação; Condous enumera alguns deles: H. Bonciu, D. H. Bonciu, Haimovici Bonciu, Bon-Tsu-Has, Sigismund Absurdul e Benjamin Bonciu (CONDOUS, 2015, p. $15)$.

Como Meyrink, também passou três meses na prisão devido à "ofensa pública" representada por seus romances Bagaj e Pensiunea doamnei Pipersberg. O endurecimento do regime fascista na Romênia, com sua sistemática perseguição aos judeus e, ato contínuo, o posterior endurecimento do regime comunista subsequente, poucos anos após o final da Segunda Guerra Mundial, somado a grave instabilidade pessoal - resultante da morte prematura da esposa - inviabilizaria a carreira de Bonciu, autor que estudou na Alemanha e teve contato direto com o expressionismo, cuja essência estética alimentou suas criações. Assim, muitas de suas obras, anunciadas em periódicos, mencionadas em cartas ou planejadas em anotações e manuscritos se perderam, de tal forma que torna-se impossível determinar se foram escritas ou se, após alguma etapa de desenvolvimento, descartadas (destruídas ou esquecidas). Condous propõem, em seu Golem of Bucharest, uma expressão conceitual para o estado desse material: Cryptadia, expressão grega que alude a "coisas que devem ser mantidas em sigilo, escondidas, ocultas" (CONDOUS, 2015, p. 20). Tratase de uma interessante estratégia de evocação - a partir dos fragmentos a respeito da obra, dispersos naquilo que Bonciu de fato escreveu, Condous procura reconfigurar a obra perdida em um trabalho que é simultaneamente evocação e criação, construção pessoal/autoral e apropriação de uma obra possível alheia. Trata-se de uma peculiar leitura, como o Golem de Meyrink em relação à tradição lendária judaica.

Dessa forma, temos um monstro bastante peculiar no "golem de Bucareste", a cobra naja de Bonciu/Condous. O romance original foi mencionado, inicialmente, no jornal Azi ("Hoje") em 1935, em anúncio que incluía um breve fragmento. Depois, foi 


\section{Arquivo Maaravi}

anunciado novamente em 1939 pela Editura Cultura Poporului ("Editora Cultura Popular"), que já havia lançado um livro de poemas de Bonciu, Brom (1939). Um novo anúncio do romance ocorreria em 1945, dessa vez pela Editura Contemporana ("Editora Contemporânea"), mas o lançamento da nova publicação foi novamente malogrado. Se, em 1939, o livro foi inviabilizado pelo endurecimento da política antissemita implementada pelo governo fascista de Ion Antonescu, em 1945 os problemas seriam de outra ordem - dessa vez, as indefinições diante do novo regime comunista e de sua política estética.

Sendo assim, o romance provavelmente estava finalizado em 1945 e foi perdido ou destruído (CONDOUS, 2015, p. 42-43). Desse modo, há a tentativa de extrapolação ficcional efetuada por Condous, que analisaremos a partir de agora. A "cobra naja" do título é apresentada logo no início do texto: trata-se de um ser extraordinário que se move camuflado como um "cidadão comum" de Bucareste, sem "nada de extraordinário para chamar a atenção" (CONDOUS, 2015, p. 44). Reside em um edifício - mesmo em um quarteirão próprio -, esvaziado e soturno, que contrasta com a pulsante atividade dos quarteirões ao redor. Esse estranho ser, que segundo o narrador teria uma moradia além de sonhos muito peculiares e que sofreria um stress terrível ao se comunicar com os seres humanos normais, teria cadernos de anotação registrando as terríveis atividades de sua mente. Nesse momento, a narrativa se quebra e adentramos um espaço negativo, o espaço do poema; nesse espaço é que constatamos os poderes da cobra, que buscam diluir pelo absurdo a percepção de suas "vítimas": "Uma nova nebulosa surgiu vomitando seu caos negro de horror. A velha caiu em uma abraço esfacelado. Agora entre no labirinto." (CONDOUS, 2015, p. 54). Não há dúvidas de que a narrativa de Bonciu reconstruída por Condous possui forte influência do Golem de Meyrink, mas a criatura aqui segue um caminho ainda mais extremo, notadamente no que diz respeito à nossa análise: ela perde ainda mais suas nuances específicas e mesmo de mito individual e torna-se uma imagem ainda mais ampla de totalidade.

Pois o Golem de Meyrink possui a sua própria infância: trata-se de quando desempenhava as funções servis para o rabino de Praga - Meyrink sequer se recordava do nome do rabino mais célebre associado ao Golem, Judá Loew ben Betzalel (1520-1609). A história segue o mito do aprendiz de feiticeiro, como usual - o descontrole da criatura útil e inofensiva que motiva sua destruição - mas há um repentino salto: “Não sei como a história do Golem surgiu, mas aqui está o que sei existe alguma coisa neste bairro... algo que não pode morrer e que está em nosso meio." (MEYRINK, 1986, p. 26). A leitura/apropriação romântica - vinculada ao aprendiz de feiticeiro e ao Quasímodo de Victor Hugo - transforma-se em projeção, imagem perene, menos monstro e muito mais síntese de estereótipos dos judeus que habitavam o gueto, do próprio gueto (enquanto ideia) e, por fim, da cidade de Praga. Esse processo ganha uma radicalização adicional em Bonciu/Condous; agora, o 
monstro já surge como uma alucinação citadina, agora transformando não apenas na essência de uma cidade (Bucareste), mas de todas elas. O narrador de Sarpele cu Ochelari parece ser a própria criatura, embora haja um perene aspecto de ambiguidade na trama; alucinação citadina a cobra haja parece ser potencialmente cada cidadão de Bucareste. Seu domínio não é mais cíclico, como o do Golem de Meyrink, mas permanente, registrado nas anotações ferozes de seus cadernos. Fantasmagorias da Cidade que - como Praga ou Bucareste - congrega em si modernidade e tradição, a imagem condensada desses monstros aproxima a percepção da identidade do judeu ao caos urbano. Mas transcende a imagem monstruosa e estereotipada do judeu - que, para o antissemita, também não possui infância por sua natureza idealizada e monstruosa - pois a cidade infinita não surge em tais narrativas rejeitada em prol de um idílio qualquer que a possa substituir; ao contrário, o convite do Golem de Meyrink e da cobra naja de Bonciu/Condous é de um "abraço esfacelado", um mergulho absoluto nessa cidade que parece compartilhar algo da imagem condensada do judeu em sua errância, exílio, solidão. No tempo do mito, sequer as cidades possuem infância, um período salutar de gestação e desenvolvimento, mas o próprio mito é um pouco o tempo da infância, a suspensão da continuidade lógica ou causal cuja exigente formatação é a tarefa árdua da História.

Assim, o tempo do Golem aqui analisado se comunica com a subjetividade, embora não dentro de um contexto exclusivo, como a ideia de "mito individual" de Scholem; o monstro que caminha entre nós, que pode ser qualquer um na multidão citadina, é uma imagem especular da subjetividade de cada leitor. Mito contemporâneo, o Golem de Meyrink (bem como sua leitura mais ousada e infelizmente apenas parcialmente concretizada, a cobra naja de Bonciu/Condous) transforma a lenda e a história judaica em sua especificidade, projetando-a, não sem contradições, em uma tela muito mais ampla e complexa, que transcende a infância não por redução simples à percepção de pânico causada pela continuidade do monstro, mas pelo que há de perene na monstruosidade subjetiva.

* Alcebiades Diniz Miguel é Doutor em Teoria e História Literária na Universidade de Estadual de Campinas e pesquisador em História e Teoria Literária.

\section{Notas}

1 “La curiosité infantile des êtres s'exprime dans leur taille remarquablement mince; ils veulent quitter la chambre, sans s'attarder sur le côté ironique de cette action, mais 
à l'instant même les jupes et les jambes s'illuminent à un puissant jeu d'artifices." (TROST, 2014, p. 344).

2 Seria possível imaginar que a segunda resposta de Leon contivesse algum tipo de ironia, mas é muito mais factível imaginar que o andróide simplesmente seguiu sua programação e indicou literalmente a natureza de sua resposta: por não ter mãe ou nada o que contar dela, os tiros disparados pelo andróide seriam a resposta adequada que colocaria um fim à entrevista e revelaria, de uma vez por todas sua natureza monstruosa.

${ }^{3} \mathrm{O}$ horror desse procedimento, instigado pelo baixo clero, foi recuperado por Heinrich Kleist no conto "O terremoto do Chile" no desfecho, carregado de horror. Embora a narrativa de Kleist não seja a respeito de um pogrom, suas imagens com certeza poderiam ser evocadas nesse sentido: "Mas Mestre Pedrillo não descansou até arrancar-lhe uma das crianças dos braços, depois girá-la ao alto e jogá-la contra uma pilastra que havia em um canto da igreja. Com isso, se apaziguou e todos se retiraram. Dom Fernando, ao ver seu pequeno Juan com os miolos derramados para fora do crânio, levantou os olhos ao céu, embargado por indizível horror." (KLEIST, 2015).

${ }^{4}$ Assim, o judeu para um antissemita só pode existir dentro de uma coletividade padronizada. Os desdobramentos mais recentes do preconceito anti-judaico - como é o caso do assim chamado "antissionismo" - derivam exatamente dessa visão contínua, que transforma todo um Estado em uma espécie de "entidade" contaminada pelo "mal" judaico.

5 "A palavra hebraica Golem designa algo sem forma e imperfeito. O dicionário, na tentativa de defini-la, faz o vocábulo proliferar em outros tantos significados: matéria disforme, massa amorfa, pessoa desajeitada; larva, pupa, embrião; casulo; robô; ignorante, estúpido; autômato legendário de barro ao qual foi soprada a vida através dos nomes sagrados; matéria bruta." (NASCIMENTO, 2004, p. 17).

${ }^{6}$ A materialização do mito era uma ideia que obsediava a literatura do século 20, como o comprava um romance como Ulysses (1922) de James Joyce. Mas a ainda pouco conhecida ou estudada literatura ocultista, com laivos neo-românticos e também vanguardistas, que surgiu na esteira do simbolismo e que se espalhou no século 20 do País de Gales (com Arthur Machen) à Rússia (Mikhail Bulgakov como exemplo), fez dessa busca matéria-prima central de suas composições. Nesse sentido, é interessante perceber como a ideia de um golem "encarnação da alma do gueto" se aproxima da ideia de Ewers de que a mandrágora deveria ser criada para que o mito ganhasse vida: “Deves criar a mandrágora [...]. Deves tornar verdade a velha lenda. Que importa que seja superstição, fantasmagoria medieval, aparato místico dos velhos tempos?" (EWERS, 1993, p. 41). 


\section{Referências}

ADORNO, Theodor; HORKHEIMER, Max. Dialética do esclarecimento: fragmentos filosóficos. Trad. Guido Antônio de Almeida. Rio de Janeiro: Jorge Zahar Ed., 2006.

ALIGHIERI, Dante. A divina comédia: inferno. Trad. Italo Eugênio Mauro. São Paulo: Ed. 34, 1998.

Bíblia de Jerusalém. São Paulo: Edições Paulinas, 1992.

BLEILER, E. F. Gustav Meyrink. In: MEYRINK, Gustav. The Golem. New York: Dover Publications, 1986.

CONDOUS, Andrew. Golem of Bucharest. Bucharest: L'Homme Recent, 2015.

CORNELSEN, Élcio. Os caminhos do Golem pela literatura. In: NAZARIO, Luiz; NASCIMENTO, Lyslei; NAZARIO, Luiz (Org.). Os fazedores de golems. Belo Horizonte: Programa de Pós-Graduação em Letras: Estudos Literários, Fale/UFMG, 2004.

EWERS, H. H. La Mandrágora. Madrid: Valdemar, 1993.

FLUSSER, Vilém. A história do diabo. São Paulo: Annablume, 2006.

HOMERO. Odisséia. Trad. Christian Werner. São Paulo: Cosac Naify, 2014.

KLEIST, Heinrich. El terremoto en Chile. In: Ciudad Seva. Disponível em $<$ http://www.ciudadseva.com/textos/cuentos/ale/kleist/el_terremoto_en_chile.htm>. Acesso em: 26 out. 2015. MEYRINK, Gustav. The Golem. New York: Dover Publications, 1986. NASCIMENTO, Lyslei. O Golem: do limo à letra. In: NAZARIO, Luiz; NASCIMENTO, Lyslei (Org.). Os fazedores de golems. Belo Horizonte: Programa de Pós-Graduação em Letras: Estudos Literários, Fale/UFMG, 2004. p. 15-37.

NAZARIO, Luiz. Da natureza dos monstros. São Paulo: Arte \& Ciência, 1998.

NAZARIO, Luiz. O ideário nazista nos filmes de Hans Steinhoff. WebMosaica: revista do Instituto Cultural Judaico Marc Chagall. Porto Alegre, v. 2 n. 2, jul.-dez., 2010.

NAZARIO, Luiz. Passeando pelos campos de concentração. In: . Reflexões sobre o mundo contemporâneo. Disponível em: $<$ https://escritorluiznazario.wordpress.com/2011/02/14/passeando-pelos-campos-deconcentracao/>. Acesso em: 26 out. 2015.

RIO, João do. A alma encantadora das ruas. Disponível em: $<$ http://objdigital.bn.br/Acervo_Digital/livros_eletronicos/alma_encantadora_das_rua s.pdf>. Acesso em: 27 out. 2015.

TROST. Le plaisir de flotter - rêves et délires. In: YAARI, Monique (Org.). "Infranoir", un et multiple. Bern: Peter Lang, 2014. 